\title{
The progressive systemic sclerosis/systemic lupus overlap: an unusual clinical progression
}

\author{
Ronald A Asherson, Heather Angus, John A Mathews, Orlando Meyers, Graham R V Hughes
}

\begin{abstract}
Three patients with the unusual combinations of discoid lupus, systemic lupus erythematosus (SLE), and progressive systemic sclerosis (PSS) are reported. The first patient developed PSS eight years after a diagnosis of discoid lupus had been made and this was complicated by myositis six years later. The second patient developed PSS more than 20 years after being diagnosed as having SLE. The third patient developed SLE with predominant features of urticarial vasculitis six years after PSS. Mild myositis also ensued. There were no antibodies to U1RNP demonstrable in any of these patients. The clinical progression of SLE to PSS or vice versa in the absence of features of mixed connective tissue disease is distinctly uncommon.
\end{abstract}

Although the connective tissue diseases can usually be clinically and serologically defined as distinct and separate entities, such as rheumatoid arthritis, systemic lupus erythematosus, progressive systemic sclerosis, and dermatomyositis, overlap between these conditions may be encountered. A specific overlap termed mixed connective tissue disease is one such condition. ${ }^{1}$ Others are simply termed undifferentiated connective tissue disease. ${ }^{2}$ Sjögren's syndrome, fibrosing alveolitis, and Raynaud's phenomenon may accompany all of the above but may also exist on their own as 'primary' conditions.

The association of lupus and scleroderma (with or without myositis), one condition merging into the other, without the presence of antibodies to UIRNP or any clinical features of mixed connective tissue disease, is distinctly uncommon. We report three such patients seen over the past five years.

The Lupus Arthritis Research Unit and Rheumatology Departments, St Thomas's Hospital, London SE1

R A Asherson J Mathews

G R V Hughes

Rheumatology Unit, Groote Schuur Hospital, Cape Town, South Africa $\mathrm{H}$ Angus

O Meyers

Correspondence to:

Dr Asherson.

Accepted for publication 28 August 1990

\section{Case reports}

PATIENT ONE: DISCOID LUPUS DEVELOPING INTO PROGRESSIVE SYSTEMIC SCLEROSIS WITH LATE COMPLICATING POLYMYOSITIS

A 48 year old white woman of Austrian ancestry had a single discoid lesion aged 21 which was confirmed as being discoid lupus erythematosus in 1975 at the age of 34 . Clinical details are sketchy, but skin manifestations had predominated. At this time her antinuclear antibodies were positive (1/320). A biopsy specimen from non-lesional skin showed positive immunofluorescence for IgG and complement, and a lesional biopsy specimen showed typical histological features of discoid lupus erythe- matosus. At this time she was given Synacthen depot. At age 42 a clinical diagnosis of progressive systemic sclerosis (PSS) was made. She now had thickening of her skin, predominantly affecting the hands, as well as Raynaud's phenomenon. She was initially given prednisolone $5 \mathrm{mg}$ twice a day. Progressive thickening of the skin continued, however, with 'cracking' of the finger tips. Despite the prednisolone, sloughing of the tips of three fingers occurred in 1983, and she was admitted to hospital for treatment and the steroids were stopped. The DNA binding at this time was normal $(7 \cdot 5$ $\mathrm{U} / \mathrm{ml}$ ) but the antinuclear antibody titre was raised at $1 / 160$. Ketanserin was given without any appreciable response. In 1985 a prostaglandin infusion was given intravenously with some improvement in the skin thickening and warmth of the hands, but the improvement was not sustained for longer than a few weeks.

In 1987 she complained of arthralgia of the shoulders, knees and, predominantly, the wrists. She was found to have soft tissue swelling of the knees and wrists, microstomia (fig 1), and dry thick fingers with pseudoclubbing, but no telangiectasias were seen. The haemoglobin was $95 \mathrm{~g} / \mathrm{l}$ with a low serum ferritin $(5.5 \mathrm{mmol} / \mathrm{l})$, the white blood cell count

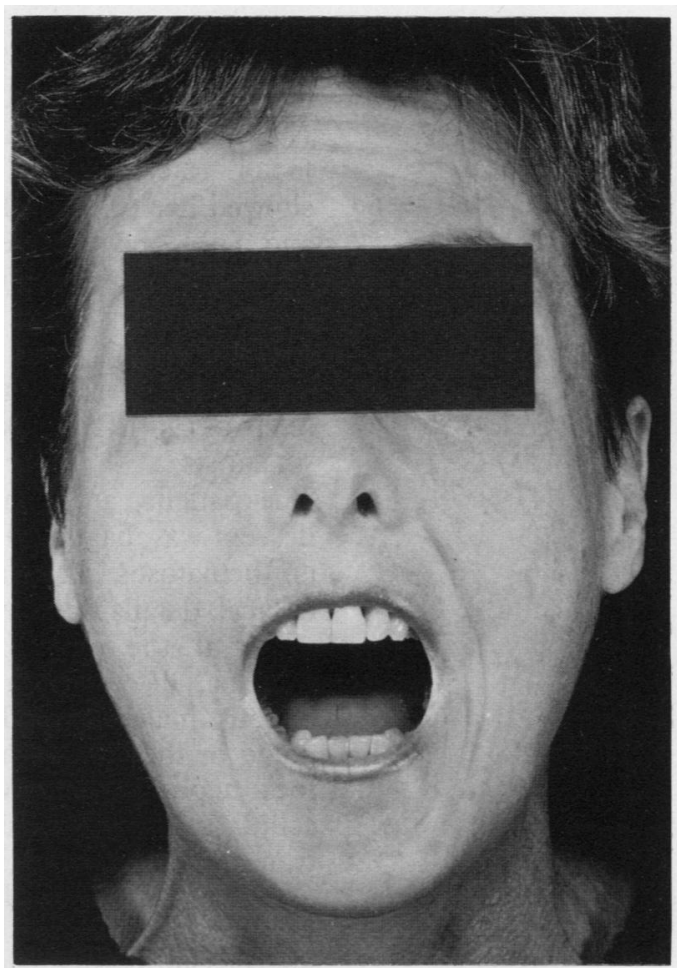

Figure 1 Patient No 1 showing microstomia. 
Figure 2 Patient No 1. Radiograph of the hands showing resorption of the terminal phalanges.

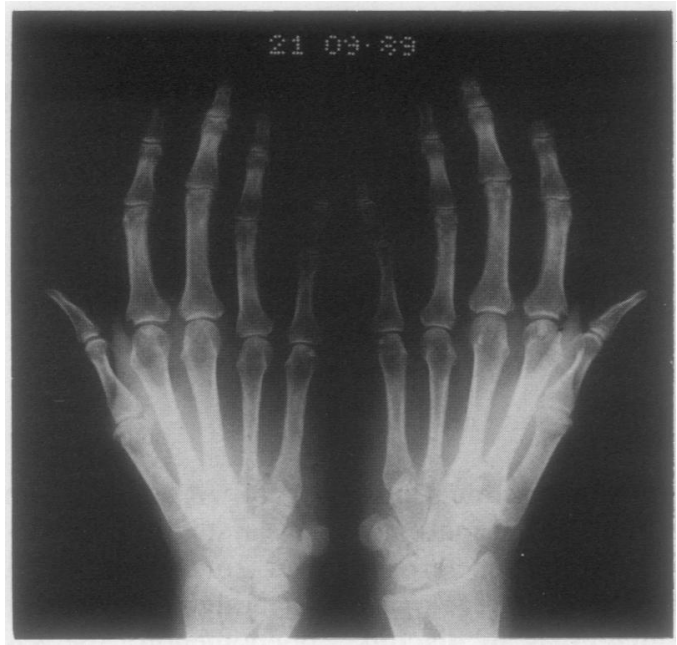

was normal but the erythrocyte sedimentation rate (ESR) was raised at $44 \mathrm{~mm} / \mathrm{h}$. The antinuclear antibody titre was still positive $(1 / 320)$, immune complexes were increased (IgG $102 \mathrm{mg} / \mathrm{l})$, she had negative latex and RoseWaaler tests for rheumatoid factor, but surprisingly antibodies to $\mathrm{Sm}$ were present. The serum IgG concentration was raised $(17.9 \mathrm{~g} / \mathrm{l})$ (normal 5.3-16.5 g/l). She was given diclofenac sodium $100 \mathrm{mg}$ twice a day for the joint pains.

Throughout 1988 and 1989 various other non-steroidal anti-inflammatory drugs were prescribed (ketoprofen, indomethacin) with no major clinical effects. A chest radiograph was normal, but radiography of her hands now showed resorption of the terminal phalanges (fig 2). There was no soft tissue calcification evident. In October 1989 she complained of muscle pain and her muscle enzymes were raised. Electromyography showed fibrillation and small polyphasic units characteristic of inflammatory muscle disease. A diagnosis of myositis was made. Her creatine kinase was $608 \mathrm{U} / 1$ (normal <250), and hydroxybutyric dehydrogenase $238 \mathrm{U} / \mathrm{l}$ (normal <182). The ESR was raised at $82 \mathrm{~mm} / \mathrm{h}$ and the rheumatoid factor test was also positive. Tissue typing showed her to be A11,28, B14,56, C4,5, Bw6, and DR1 and 6. The muscle symptoms have responded to prednisolone $5 \mathrm{mg}$ twice daily.

PATIENT TWO: SYSTEMIC LUPUS ERYTHEMATOSUS DEVELOPING INTO PROGRESSIVE SYSTEMIC SCLEROSIS

The patient, a South African man of mixed descent was diagnosed as having systemic lupus erythematosus (SLE) at the age of 9 years, but clinical details are available only from 1973, when at the age of 17 he presented with alopecia, discoid skin lesions, and an erythematous malar rash. Blood and protein were noted in the urine, and a renal biopsy showed focal nephritis, with wire looping, focal hypercellularity, and subendothelial deposits on electron microscopy. The haemoglobin was $105 \mathrm{~g} / 1$, urea $23 \mathrm{mmol} / \mathrm{h}$, and creatinine $272 \mu \mathrm{mol} / \mathrm{l}$. Lupus erythematosus cells were positive, antinuclear antibodies were positive at a titre of $1 / 100$, and rheumatoid factor was negative. He was treated with prednisolone (60 mg/day) and cyclophosphamide (125 mg/day orally) with improvement. Cyclophosphamide was stopped after three months because of the development of haemorrhagic cystitis.

He was lost to follow up until 1982 when he was admitted with right middle lobe pneumonia. Extensive skin lesions of chronic discoid lupus affecting the scalp, face, and upper trunk with scarring and alopecia were noted.

A loud pericardial friction rub was noted, and echocardiography confirmed a pericardial effusion.

The haemoglobin was reduced at $82 \mathrm{~g} / \mathrm{l}$, the total white cell count was $11 \cdot 3 \times 10^{9} / 1$ with $17 \%$ lymphocytes, and platelets were $729 \times 10^{9} / 1$. The ESR was $125 \mathrm{~mm} / \mathrm{h}$. The urea was $3.8 \mathrm{mmol} / \mathrm{l}$, creatinine $71 \mu \mathrm{mol} / 1$, with an uncorrected clearance of $132.3 \mathrm{ml} / \mathrm{min}$ and a 24 hour urinary protein excretion of $0.12 \mathrm{~g}$. The antinuclear antibody titre was low positive (1/10), and antiDNA antibodies raised at $10 \mathrm{mg}$ bound DNA $/ \mathrm{ml}$ serum (normal 0-5). Radiographs of the hands were normal. He was treated with prednisolone $(40 \mathrm{mg} /$ day $)$ and antibiotics for his infection.

In 1985 he presented to the outpatient clinic with pleuritic chest pain and arthralgia. Synovitis of the wrists and the metacarpophalangeal and proximal interphalangeal joints of the hands was noted, and radiographs showed juxtaarticular osteoporosis, but no erosions. Sclerodactyly was noted for the first time. The antinuclear antibody titre was positive (1/100; 1/500) (homogeneous), and anti-DNA antibodies were raised at $18 \mathrm{mg}$ bound $\mathrm{DNA} / \mathrm{ml}$ serum. Treatment with chloroquine phosphate (250 $\mathrm{mg} /$ day) was started for control of his arthritis.

Throughout 1986 and 1987 he continued to have pain in the hands and wrists, but no active arthritis was reported. The sclerodactyly became more marked, however, and he developed proximal scleroderma with skin changes extending onto the forearms. Marked resorption of the digits resulted in significant loss of hand function. Radiographs of the hands over a three year period showed progression of erosions and marked resorptive changes at the interphalangeal and metacarpophalangeal joints, as well as the wrists (figs $3 \mathrm{~A}, \mathrm{~B}$, and $\mathrm{C}$ ).

The patient has never had Raynaud's phenomenon. The nailfold capillaries could not be clearly seen owing to the pigmentation and thickening of the skin. There was no evidence of skin telangiectasia or calcinosis. He did not have dysphagia, and a barium swallow done in September 1988 was normal. Tolerance of exercise was normal and the chest was clinically and radiologically clear.

There had been no evidence of active lupus for the past two years. The skin lesions were quiescent, he did not have serositis, and the urine was clear. The most recent laboratory investigations showed haemoglobin $154 \mathrm{~g} / \mathrm{l}$, white blood cell count $7.6 \times 10^{9} / 1$ with a normal differential, platelets $275 \times 10^{9} / 1$, ESR $12 \mathrm{~mm} / \mathrm{h}$, urea $4.6 \mathrm{mmol} / \mathrm{l}$, and creatinine $77 \mu \mathrm{mol} / \mathrm{l}$. A 24 hour urine collection was negative for protein, and the uncorrected clearance was $131 \mathrm{ml} / \mathrm{min}$. Recent serological tests showed a negative 


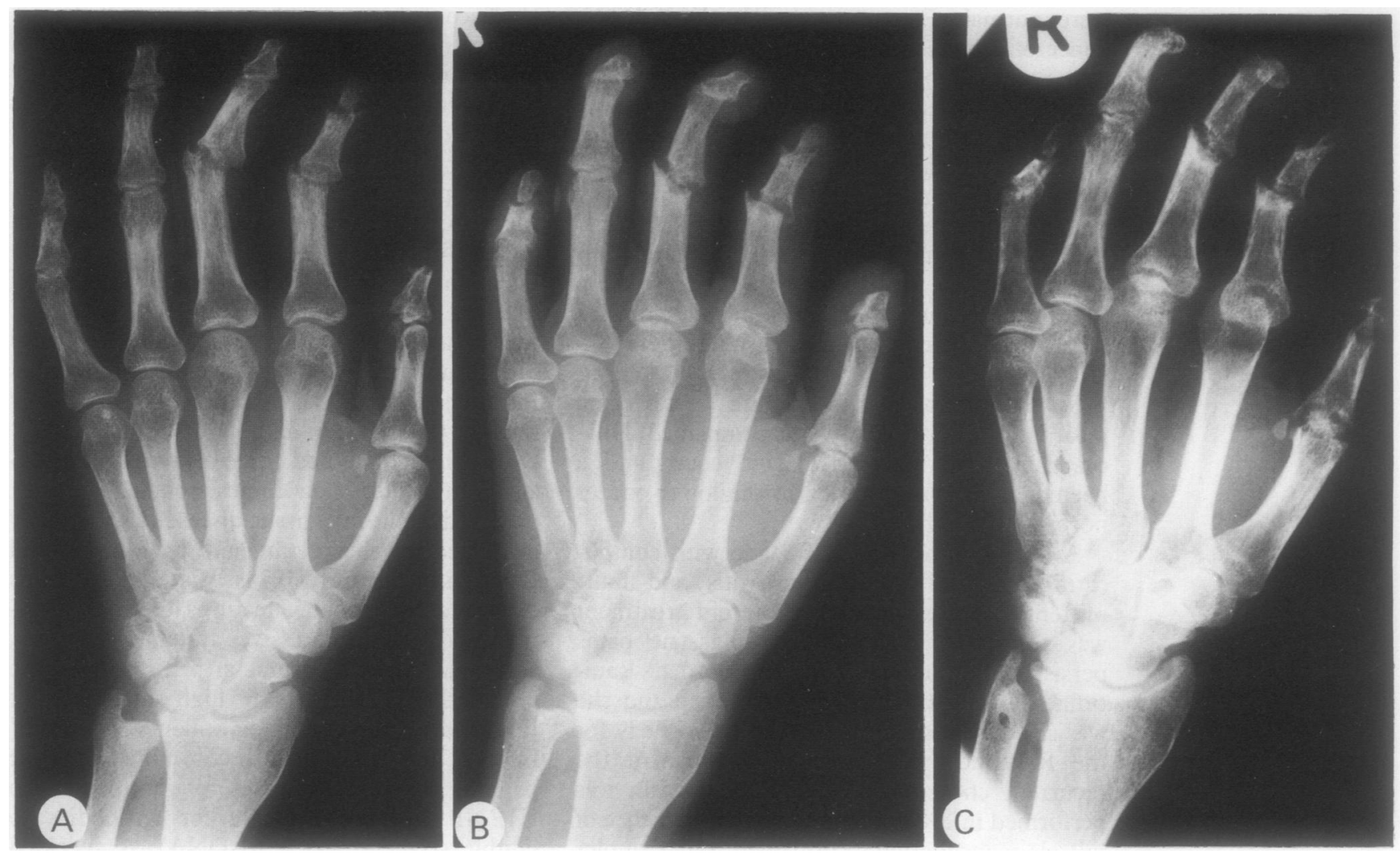

Figure 3 Patient No 2. Radiograph of the right hand in $(A)$ December 1986; (B) November 1987; (C) October 1988.

antinuclear antibody and anti-Ro antibody. Anti-DNA antibodies were normal $(<3 \mathrm{mg}$ bound DNA $/ \mathrm{ml}$ serum) and other antibodies to extractable nuclear antigens were also negative. The patient was once again lost to follow up and skin biopsy specimens were unobtainable.

PATIENT THREE: PROGRESSIVE SYSTEMIC SCLEROSIS DEVELOPING INTO SYSTEMIC LUPUS ERYTHEMATOSUS

The patient, a 42 year old white woman with no family history of note, had a six year history of polyarthritis and polyarthralgias affecting mainly the ankles, knees, and small joints of the hands, thickening of the skin, particularly affecting the face, upper arms, and shoulders, accompanied by Raynaud's phenomenon. Exertional dyspnoea had recently developed over one year as well as 'indigestion', which consisted of substernal burning and discomfort postprandially. Additionally, she was lethargic. She had a longstanding history of dermatographism.

When seen in 1985 she had the typical features of scleroderma-including shiny and taught skin over the digits and loss of digital creasing-accompanied by synovitis, particularly of the metacarpophalangeal joints of both hands. There were no associated pigmentary changes, but microstomia was present. She additionally had livedo reticularis.

From 1987 she had an intermittent burning purpuric rash generalised in distribution, which was diagnosed as urticarial vasculitis, for which she was given a course of dapsone in 1986 . Hair loss started some three years after the onset of her illness. She was given steroid treatment, but in 1987 developed steroid induced glaucoma. To reduce her steroid requirements, hydroxychloroquine and naproxen were added to her regimen for relief of her arthritic pains. Several 'flares' of disease had occurred over the six year period, which were associated with increased shortness of breath but without cough, and the dyspnoea was accompanied by severe arthralgias.

These 'flares' had previously been treated with temporary increases in steroid dose. She had recently had more frequent episodes of retrosternal chest pains radiating to her neck and occurring particularly at night. She was admitted to St Thomas's Hospital for assessment in April 1987. Alopecia was noted as well as a widespread fading urticarial rash affecting the limbs and trunk. There was a purpuric element present on the edges of the soles of the feet and toes. Microstomia was obvious but no sclerodactyly was present.

Investigations showed a normal blood count with an ESR of $17 \mathrm{~mm} / \mathrm{h}$ and a raised platelet count of $519 \times 10^{9} /$. Coombs' test was negative. The Crithidia DNA immunofluorescence test was positive. Antinuclear antibodies were positive at 1/320 and the DNA binding antibody was more than $97 \mathrm{U} / \mathrm{ml}$ (normal $<25 \mathrm{U} / \mathrm{ml}$ ). The Venereal Disease Research Laboratory test was negative. Immune complexes were raised at $116 \mathrm{~g} \mathrm{IgG/1}$ (normal <49). The aspartate transaminase was minimally raised and the hydroxybutyric dehydrogenase activity was also increased. The creatine kinase was persistently normal. Liver function and renal function tests 
were normal. Electromyography showed evidence of a mild myositis with some polyphasicity. Radiographs showed normal heart size and lung fields. Barium swallow and meal examinations were normal. No erosive changes were evident in the hands, and there was no terminal resorption of bone and no calcinosis. There was minor subluxation of the distal interphalangeal joints of both little fingers. Respiratory function tests showed a mild restrictive defect with a significant reduction in gas transfer (transfer factor 5.3) (predicted mean value (SD) 8.5 $(2 \cdot 4))$.

Several months later the Coombs' test became positive. This positivity was accompanied, however, by a normal reticulocyte count and a haemoglobin concentration at the lower end of normal (125 $\mathrm{g} / \mathrm{l})$.

A diagnosis of SLE was made with complicating urticarial vasculitis, myositis, and intermittent Coombs' positivity. Steroid treatment was continued. Postprandial epigastric pains persisted, but an endoscopy was normal. Ranitidine $150 \mathrm{mg}$ twice a day was added and she was also given nifedipine $20 \mathrm{mg}$ twice a day for the Raynaud's phenomenon. Because of the recurrent chest pains an echocardiogram was performed in 1988. This showed the presence of mitral regurgitation, confirmed on Doppler scanning.

When seen in late 1988 she had developed marked telangiectasias of the face and hands but there was no evidence of a CREST syndrome, such as pigmentation or sclerodactyly, and the telangiectasis were ascribed to her long term steroid treatment. Microstomia was still present. Immunological testing now showed antibodies to extractable nuclear antigens (unidentified), and the rheumatoid factor was positive. The C4 concentration was reduced at $0 \cdot 11 \mathrm{~g} / 1$ (normal $0 \cdot 16-0.45$ ) with a low normal $\mathrm{CH} 100$ of $60 \%$ (normal $50-125$ ) and $\mathrm{C} 3$ at $0.8 \mathrm{~g} / 1$ (normal 0.7-1.8). Antimitochondrial antibodies were negative and the Coombs' test was now negative. $\mathrm{Clq}$ precipitins were present in serum. A lymphopenia of $0.9 \times 10^{9} / 1$ had developed (normal 1.5-3.5 $\times 10^{9} / 1$ ).

The patient continues to have episodes of recurrent urticarial vasculitis unresponsive to most treatments.

\section{Discussion}

The three patients described present unusual overlap features of two well defined connective tissue diseases. Patient one originally presented with discoid lupus and there was no convincing evidence of systemic disease. Eight years later she had features of PSS predominantly affecting the skin, and severe Raynaud's phenomenon. Interestingly, in 1987, 12 years after the initial development of discoid lupus erythematosus and still with predominant features of PSS, antibodies to $\mathrm{Sm}$ were present, indicating that at least serologically there was some evidence of antibody production against ribonucleoproteins, not usually seen in PSS, indicative and diagnostic of coexisting SLE.

Patient two developed SLE at a young age. Eight years later he presented extensive features of discoid lupus erythematosus and then a clinical picture of PSS seemed to evolve with marked resorption of digits. An unusual feature was the fact that he never experienced Raynaud's phenomenon. He lived in a warm climate, however, and the fact that he was naturally racially pigmented might have made any observations of colour changes associated with vasospasm difficult.

Patient three developed typical features of SLE six years after manifesting PSS. The SLE was heralded by the appearance of the typical rash of urticarial vasculitis, which has persisted for three years and has been unresponsive to any form of treatment to date.

In patients one and three a myositis eventually complicated their clinical course.

Mixed connective tissue disease was originally described by Sharp et $a l^{3}$ and by Mattioli and Reichlin in the early 1970s. ${ }^{1}$ Patients with this disease seem to show features of SLE, polymyositis, and progressive systemic sclerosis, accompanied by a chronic arthritis at one time or another. There is a high incidence of Raynaud's phenomenon, swollen or 'sausage' fingers, and tenosynovitis clinically. All these patients have high titres of antibodies to U1RNP and are negative for antibodies to double stranded DNA (dsDNA). A speckled pattern of antinuclear antibodies is a useful clue to the presence of antibodies to UIRNP. The incidence of renal disease and neuropsychiatric illness in this group seems to be low according to some studies. Younger patients with the condition tend to develop SLE, whereas older patients develop features of progressive systemic sclerosis. Many, however, remain in the category of mixed connective tissue disease.

The familial occurrence of SLE and scleroderma is well described. Flores et al reported eight families containing members with both disorders. ${ }^{4}$ Relatives with PSS, however, had at least one serological abnormality more characteristic of SLE, such as antibodies to Sm, antiRNP, anti-dsDNA, haemolytic anaemia, leucopenia, or hypocomplementaemia. Two members of different families had enough clinical evidence of both diseases simultaneously to classify them as such.

Other authors have also drawn attention to the coexistence of both PSS and SLE within families, ${ }^{5-7}$ and these patients are discussed in detail by Flores et al. ${ }^{4}$

Dubois et al reported PSS and SLE coexisting in the same patients. ${ }^{7}$ These authors reviewed the incidence of coexistent SLE and scleroderma, as well as cases reported by other authors, and were able to discover only 10 previously published cases. They recorded 12 of 78 patients with PSS from their own clinics, nine with PSS and three with morphoea only. Definite skin changes of scleroderma were confirmed by biopsy in nine of the 12 . Discoid lupus erythematosus lesions were present in four, pleurisy in six, pleural effusions in five, and pericarditis in five. Seven had a leucopenia $\left(<4.5 \times 10^{9} / 1\right)$ and the diagnosis of the two conditions in single patients was confirmed by necropsy in four.

In an appendix to their paper Dubois et al 
then described several other patients in detail who seemed to have varying combinations of the two diseases; either PSS, later developing features of SLE, or the reverse. These patients closely resemble the patients we have reported in this paper.

Chorzelski and Jablonska also described three cases of coexistent PSS and SLE, ${ }^{8}$ one with discoid lupus erythematosus and two with SLE. Jablonska et al subsequently reviewed the coexistence of the two conditions and concluded that the association was most uncommon, occurring in less than $1 \%$ of cases of PSS. ${ }^{9}$

In summary, therefore, although the association of the two diseases in the same patient may occur rarely and sporadically, the familial occurrence of the two conditions may also be seen, albeit uncommonly.

Thanks are due to Mrs Caroline Hesketh for the typing. This work was supported by the British SLE Aid Group and the Jean Whark was supported
1 Reichlin M, Mattioli M. Correlation of a precipitin reaction to an RNA protein antigen and a low prevalence of nephritis in patients with systemic lupus erythematosus. $N$ Engl $\mathcal{F}$ in patients with systemic

2 Bennett R M. Mixed connective tissue disease and other overlap syndromes. In: Kelly W M, Harris E D, Ruddy S, Sledgde M N, eds. Textbook of rheumatology. 3rd ed. Philadelphia: Saunders, 1989: 1147-65.

3 Sharp G C, Irving W S, Tan E. Mixed connective tissue disease: an apparently distinct rheumatic disease syndrome associated with a specific antibody to an extractatle nuclear antigen (ENA). Am $\mathcal{f}$ Med 1972; 52: 148-59.

4 Flores R H, Stevens M B, Arnett F C. Familial occurrence of progressive systemic sclerosis and systemic lupus erythematosus. I Rheromatol 1984; 11 : 321-3.

5 Hagberg B, Leonhardt T, Skogh M. Familial occurrence of collagen diseases, progressive systemic sclerosis and systemic lupus erythematosus. Acta Medica Scandinavica systemic lupus ery

6 Tuffanelli $\mathrm{D}$ L. Scleroderma, immunologic and genetic disease in three families. Dermatologica 1969; 138: 93-104.

7 Dubois E L, Chandor S, Friou G J. Progressive systemic sclerosis and localised scleroderma (morphoea) with positive LE cell test and unusual systemic manifestations compatible with systemic lupus erythematosus. Medicine (Baltimore) 1971; 50: 199-222.

8 Chorzelski T, Jablonska S. Co-existence of lupus erythematosus and scleroderma in light of immunopathological investigations. Acta Derm Venereol (Stockh) 1970; 50: 81-5.

9 Jablonska S, Chorzelski T, Blasczyck M. Relation between scleroderma and collagen diseases. In: Jablonska S, ed. Scleroderma and pseudoscleroderma. 2nd ed. Warsaw: Polish Medical Publishers, 1975: 35-51. 